\title{
CARACTERIZAÇÃO DA EPIDEMIA DE HIV/AIDS NO ESCUDO DAS GUIANAS E POSSÍVEL INFLUÊNCIA DAS MIGRAÇÕES NA DISSEMINAÇÃO DO VÍRUS
}

\section{CHARACTERIZATION OF THE HIV/AIDS EPIDEMIC IN THE GUIANA SHIELD AND THE POSSIBLE INFLUENCE OF MIGRATION ON THE SPREAD OF THE VIRUS}

\author{
Flavia Divino \\ Fundação Oswaldo Cruz, Instituto Oswaldo Cruz, RJ, Brasil \\ fcpdivino@gmail.com \\ Paulo Peiter \\ Fundação Oswaldo Cruz, Instituto Oswaldo Cruz, RJ, Brasil \\ paulopeiter@gmail.com
}

\begin{abstract}
RESUMO
De 1980 a junho de 2020, foram notificados 1.011 .617 casos de AIDS no Brasil, (Ministério da Saúde, 2020) e há alguns anos que se verifica uma estabilização na taxa de incidência na América Latina, entretanto são grandes as diferenças regionais no Brasil. As regiões Norte e Nordeste ainda apresentam uma progressão nas taxas de incidência de HIV e não obstante, existe uma variante do HIV-1 do subtipo $B$, a variante BCAR (B Caribe), que anteriormente era conhecida por sua circulação restrita às ilhas do Caribe e em estudos recentes demonstrou-se sua alta prevalência nos países do Escudo das Guianas. São regiões intimamente ligadas ao Caribe e compartilham em suas fronteiras: culturas, construções sociais, políticas e uma evidente ascensão do HIV e novos casos de AIDS notificados. As mudanças no perfil da AIDS no Brasil vêm mostrando o aumento da transmissão por via heterossexual, uma prevalência de jovens de 15 a 39 anos infectados e uma epidemia que evidencia o desequilíbrio entre as regiões do país. Esses resultados também apontam fortes ligações epidemiológicas entre os países do extremo norte do continente sul-americano, os municípios fronteiriços brasileiros, mobilidade populacional, migração e a epidemia de HIV/AIDS.
\end{abstract}

Palavras chaves: HIV. AIDS. Fronteira Brasil-Guiana Francesa. Escudo das Guianas

\begin{abstract}
From 1980 to June 2020, 1,011,617 AIDS cases were reported in Brazil, (Ministry of Health, 2020) and for some years there has been a stabilization in the incidence rate in Latin America, however there are great regional differences in Brazil. The North and Northeast regions still show an increase in HIV incidence rates and, nevertheless, there is a variant of HIV-1 of subtype $B$, the variant BCAR (B Caribbean), which was previously known for its circulation restricted to the Caribbean islands and recent studies have shown its high prevalence in the countries of the Guiana Shield. They are regions closely linked to the Caribbean and share on its borders: cultures, social and political constructions and an evident rise in HIV and new AIDS cases reported. The changes in the AIDS profile in Brazil have shown an increase in heterosexual transmission, a prevalence of young people aged 15 to 39 years and an epidemic that shows the imbalance between regions in the country. These results also point to strong epidemiological links between the countries in the far north of the South American continent, the Brazilian border municipalities, population mobility, migration and the HIV AIDS epidemic.
\end{abstract}

Keywords: HIV. AIDS. Brazil-French Guiana Border. Guyana Shield

Recebido em: 13/01/2022

Aceito para publicação em: 27/01/2022.

$\begin{array}{lllll}\text { Hygeia Uberlândia - MG } \quad \text { Edição especial: X GeoSaude } & \text { Fev./2022 } & \text { p. 74-86 } & \text { Página } 74\end{array}$




\section{INTRODUCAO}

A história recente das doenças sexualmente transmissíveis no Brasil esteve atrelada aos movimentos sociais, a preconceitos culturais e aos contextos econômicos e políticos(HOCHMAN; ARMUS, 2004). No Brasil, a AIDS teve seus primeiros casos identificados no início da década de 1980, primeiramente nas principais cidades da região Sudeste onde os primeiros estudos evidenciaram uma epidemia principalmente restrita às grandes metrópoles - Rio de Janeiro e São Paulo - e de predominância masculina, atingindo prioritariamente homens com prática sexual homossexual/bissexual e indivíduos hemofílicos(Brasil Ministério da Saúde - Departamento de DST, 2016).

De acordo com estimativas do Ministério da Saúde, cerca de 1.011 .617 casos de AIDS foram notificados no Brasil desde o primeiro caso da doença até junho de 2020 (BRASIL, 2020). Verifica-se uma estabilização na taxa de incidência da doença no Brasil nos últimos 10 anos, registrando-se uma média de 20,7 novos casos de AIDS por 100 mil habitantes. Existem, entretanto, importantes diferenças regionais que devem ser consideradas. Entre 2006 e 2015 houve uma importante queda na taxa de incidência de $23,4 \%$ na região Sudeste, uma queda de $7,4 \%$ na região Sul e uma estabilização da taxa na região Centro-Oeste. Por outro lado, no mesmo período, houve um aumento de $37.2 \%$ da taxa de incidência na região Nordeste e de $61.4 \%$ no Norte (BRASIL, 2019).

Nas regiões da fronteira internacional do norte do país, a dinâmica da epidemia do HIV apresenta particularidades que precisam ser melhor estudadas, para seu efetivo controle. Análises filogeográficas de Máxima Verossimilhança revelaram a presença de uma variante caribenha em ampla circulação no extremo norte do Brasil, principalmente Roraima onde mais $40 \%$ do HIV circulante indicam introduções desde a Hispaniola, Guiana Francesa e Guiana entre o final dos anos 70 e início da década de 80(DIVINO, 2016; DIVINO 2017).Se por um lado o limite internacional se constitui em barreira à determinados fluxos entre os países vizinhos, por outro, as populações criam redes econômicas, e sociais transfronteiriças. Nesse sentido, a circulação dos vírus e outros patógenos não se interrompe na linha do limite internacional, mas a circulação de dados e informações epidemiológicas não têm a mesma facilidade de transpor limites, pois seus fluxos são regulados por normas internas a cada país, o que pode dificultar uma visão integral das epidemias(PEITER, 2005).

Durante as últimas décadas, o fluxo de pessoas nas áreas de fronteira, o garimpo no extremo norte, profissionais do sexo que atuam nessas áreas e as miseráveis condições de vida da maioria da população das áreas de fronteira podem ter facilitado uma pouco compreendida rede de infecções e disseminação do vírus. A sobrecarga nos serviços de saúde em municípios de fronteira pela importação de pacientes dos países lindeiros, ou o acompanhamento e a adesão ao tratamento doenças que requerem tratamento longo como aponta Peiter é um outro problema ligado às zonas de fronteira (PEITER, 2005).

O Escudo das Guianas é uma região peculiar situada ao norte do continente sul-americano e se distribui entre Brasil, Guiana Francesa, Suriname, Guiana e uma parte da Venezuela. Em território brasileiro o Escudo das Guianas abrange parte do estado do Amazonas, parte do Pará e os estados de Roraima e Amapá. Todas essas regiões podem ter influenciado de algum modo na propagação e disseminação do HIV e de outras doenças sexualmente transmissíveis, por se tratar de áreas com intenso fluxo de migrações de diversos povos e contato direto com populações de outros países inclusive.

A história da AIDS é uma janela que nos permite analisar problemas mais gerais que afligem hoje a saúde e a sociedade e a sua situação na fronteira explicitam mais ainda uma diferenciação regional, pois mesmo chegando nas regiões fronteiriças com alguns anos de atraso, o número de casos novos de AIDS registrados no Ministério da Saúde cresce desde o seu aparecimento, em 1980, para cada ano que passa com rapidez. A taxa de incidência nas cidades gêmeas e nas cidades de fronteira do Arco Norte é tão elevada quanto a própria região norte do país.

O questionamento que fica é: Até que ponto a propagação do vírus em alguns estados da região Norte do Brasil e suas fronteiras internacionais tem a ver com as grandes migrações e mobilidade populacional que existem entre os países que fazem fronteira com o nosso território no extremo norte

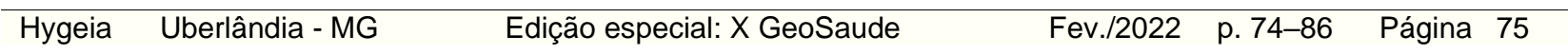


e quais os determinantes que influenciaram e influenciam até hoje a disseminação do vírus HIV nessas regiões de fronteira.

\section{METODOLOGIA}

Trata-se de um estudo descritivo fundamentado na abordagem dos determinantes sociais da saúde (WHITEHEAD, 1992). Uma organização e análise de dados secundários disponíveis em bancos de dados demográficos e de saúde de domínio público, bem como de levantamento bibliográfico. Serão utilizados dados do Instituto Brasileiro de Geografia e Estatistica (IBGE) e dados atualizados do Programa Conjunto das Nações Unidas sobre HIV/AIDS (UNAIDS) criado em 1996, cujo objetivo era ajudar os países associados no combate à AIDS. Também serão utilizados dados dos Boletins Epidemiológicos da Secretaria de Vigilância em Saúde do Ministério da Saúde, com publicação anual, para a caracterização dos estados do Amapá, Roraima e Pará.

Os dados de HIV/AIDS municipais foram obtidos nos Cadernos de Informação de Saúde e nos Indicadores Municipais - Datasus. Foram privilegiados dados secundários e as análises organizadas em seções. A primeira seção caracteriza a epidemia de HIV/ AIDS na América Latina, Caribe e Brasil. Dos bancos de dados da UNAIDS (disponíveis em < http://AIDSinfo.unAIDS.org/>), foram obtidos dados atualizados das estimativas do número de pessoas vivendo com HIV, o número atualizado das novas infecções, números dos novos casos de AIDS e óbitos relacionados a doença e o número de crianças em tratamento. Através de artigos e dados disponíveis no próprio banco de dados da UNAIDS, foi feito uma classificação das pessoas infectadas com o vírus por categorias específicas. Os dados foram organizados nas seguintes categorias: "Homens que fazem sexo com homens" (HSH), pessoas infectadas em relações extraconjugais, transgêneros, grupos de profissionais do sexo, usuários de drogas injetáveis, e o restante da população correspondente à via de transmissão heterossexual.

A segunda seção caracteriza a epidemia nos principais países que fazem fronteira direta com o Brasil no extremo norte: Venezuela, Guiana e Suriname. Para o presente capitulo foram utilizados dados atualizados da UNAIDS (disponível em < https://www.unAIDS.org/en/regionscountries/countries >), em combinação com dados secundários de boletins e artigos. Também disponíveis na plataforma do Programa das Nações Unidas.

A terceira seção foi destinada à Guiana Francesa, por sua particularidade enquanto região pertencente à um país da União Europeia na América do Sul. A Guiana Francesa faz fronteira com o Brasil e o Suriname e pertence a França. Os dados secundários atuais da epidemia neste território foram retirados de uma revisão publicada recentemente que aborda números e informações de teor semelhante aos demais países fronteiriços do Brasil (NACHER et al., 2020).

Os dados do Boletim Epidemiológico (BRASIL, 2019) foram utilizados para a organização da caracterização da quarta seção referente à Região Norte. O Departamento de DST, AIDS e Hepatites Virais (DAHV) disponibiliza periodicamente informações essenciais do HIV/ AIDS, principalmente os casos de AIDS em períodos específicos e casos de HIV notificados no Sistema de Informação de Agravos de Notificações (SINAN). Além desses dados, identificou-se o nível de escolaridade predominante nas populações e via de transmissão predominantes de infecção. Foram utilizados boletins dos anos anteriores a fim de comparações e estudo da evolução da pandemia no País e na região observada.

Nesse mesmo capitulo foram organizados dados secundários referentes à caracterização da população dos municípios, em conjunto com a caracterização da epidemia de HIV/AIDS em uma única tabela. Dados do último censo do IBGE (2010) e população estimada em 2019 foram combinados em indicadores específicos julgados importantes para o estudo de mobilidade populacional e migrações. As variáveis analisadas referem-se aos seguintes aspectos sociodemográficos: composição da população, deslocamento, características dos domicílios, educação, migração e nupcialidade. Estas variáveis foram 32 correlacionadas com as características locais e regionais da epidemia no que se refere à: casos de AIDS, casos de HIV, escolaridade predominante dos infectados pelo HIV e via de transmissão predominantes.

\begin{tabular}{llllll}
\hline Hygeia & Uberlândia - MG & Edição especial: X GeoSaude & Fev./2022 & p. 74-86 & Página 76
\end{tabular}


Para os dados específicos relacionados à AIDS e HIV dos municípios, foram utilizados dados do DATASUS, disponibilizados pela Secretaria de Vigilância em Saúde do Ministério da Saúde (disponível em < www.AIDS.gov.br/indicadores $>$ ), e para os dados demográficos municipais foram utilizados os arquivos municipais do IBGE (disponíveis em < https://cidades.ibge.gov.br/ >).

Por último, foi criada uma tabela informativa das taxas médias de incidência de AIDS no período de 2015 a 2019 (últimos 5 anos) nos estados e em cada município da área de estudo.

\section{RESULTADOS}

\section{América Latina, Caribe e Brasil}

As taxas de novas infecções pelo HIV na América Latina e no Caribe permaneceram estáveis até 2015, voltando a crescer nos anos posteriores. Porém, essa estabilidade oculta algumas diferenças. Estimase que há 2,1 milhões de pessoas vivendo com HIV na América Latina e 330 mil pessoas nesta mesma condição nas regiões do Caribe (Figura 1).

No último ano de 2019, foram contabilizadas mais de 37 mil mortes devido ao estágio de AIDS na América Latina, 6.900 mil mortes no Caribe e mais de 14 mil casos notificados de AIDS seguidos de óbitos no Brasil. Tanto na América Latina, Caribe e no Brasil, mais de $60 \%$ dos adultos infectados estão em tratamento, porém menos de $50 \%$ das crianças estão sendo acompanhadas pelo sistema de saúde. No Brasil, não são encontrados os dados do número de crianças infectadas em tratamento.

O Brasil representa uma das instabilidades observadas na América Latina quando se é observada as taxas de novas infecções, possuindo diferenças significativas em relação a taxa de detecção de AIDS (/100mil habitantes) e percentual de declínio ou incremento em períodos específicos. O mais recente período contabiliza dados de 2008 a 2018, demonstrando constante aumento nos números de casos nas regiões Norte e Nordeste (BRASIL, 2019).

Figura 1. Caracterização da epidemia de HIV/AIDS na América Latina; Caribe e Brasil, 2020

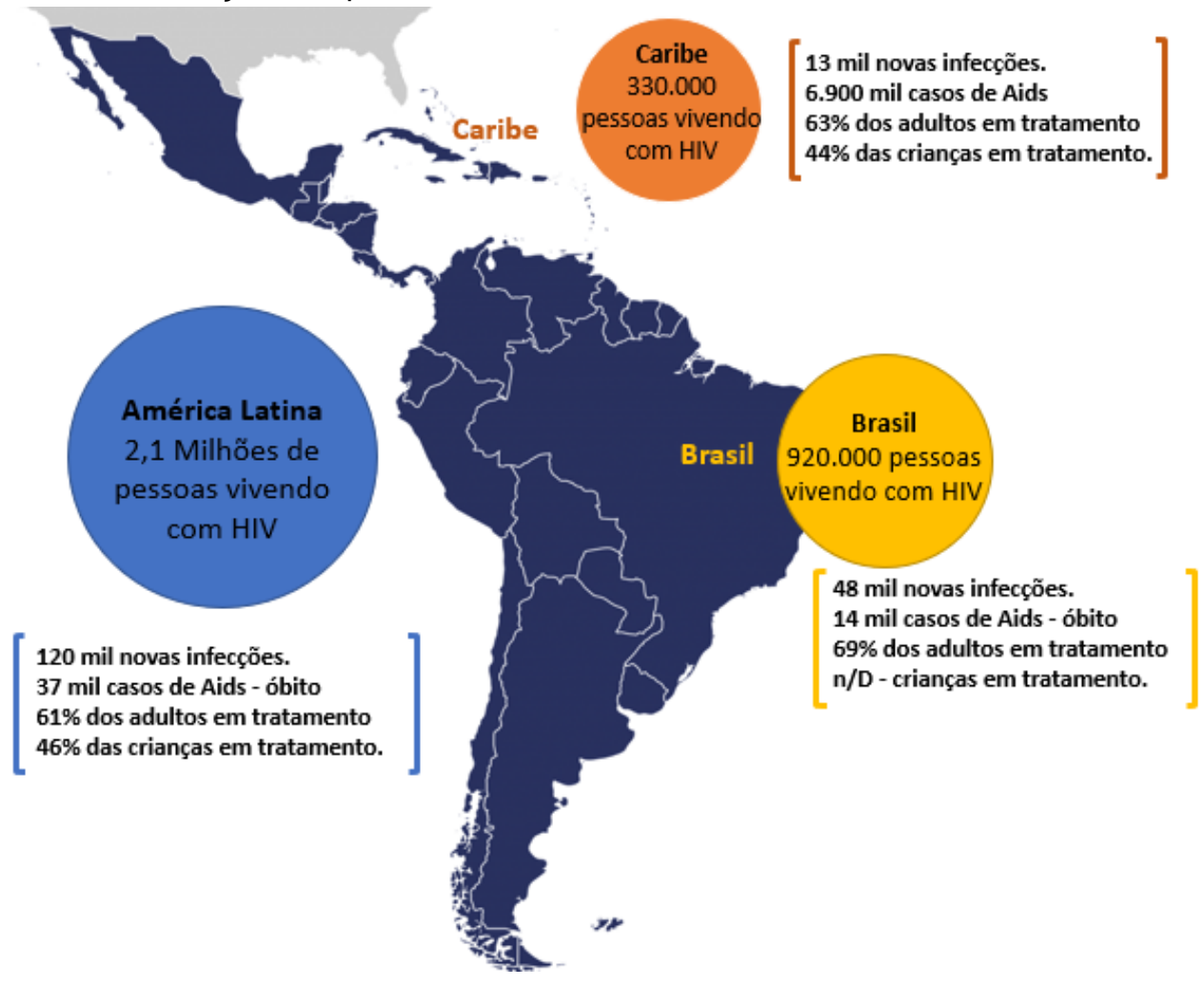

Fontes: UNAIDS - 2020. 
O Caribe conta com a $2^{\underline{a}}$ maior prevalência de HIV depois da África Subsaariana, tendo uma porcentagem de pessoas com cargas virais suprimidas abaixo da média global. Os números da América Latina e Caribe (2,1 milhões +330 mil pessoas) equivalem a uma prevalência de $0,4 \%$ na América Latina e 1,2\% no Caribe. Mesmo com alta adesão ao tratamento e uma baixa no número de mortes devido ao quadro de AIDS, as novas infecções são as que mais preocupam autoridades locais.

O Haiti, mesmo em tamanho geográfico muito menor, é o responsável por quase metade das novas infecções anuais por HIV e mortes relacionadas a AIDS. A prevalência do vírus em mulheres jovens é mais que o dobro dos homens mais jovens e os riscos em homens jovens estão mais focalizados em grupos de HSH (Figura 2). Em todo o território do Haiti, culturalmente mulheres entre 15 e 24 anos fazem sexo com homens mais velhos na maioria das vezes sem proteção, aumentando então o risco de infecção pelo HIV(AVERT, 2015). É o Haiti também que conta com a maior porcentagem de profissionais do sexo notificadas infectadas por HIV (13\%) (Figura 5.2).

Figura 2. Caracterização de grupos especificos relacionado a epidemia de HIV/AIDS na América Latina; Caribe e Brasil, 2020

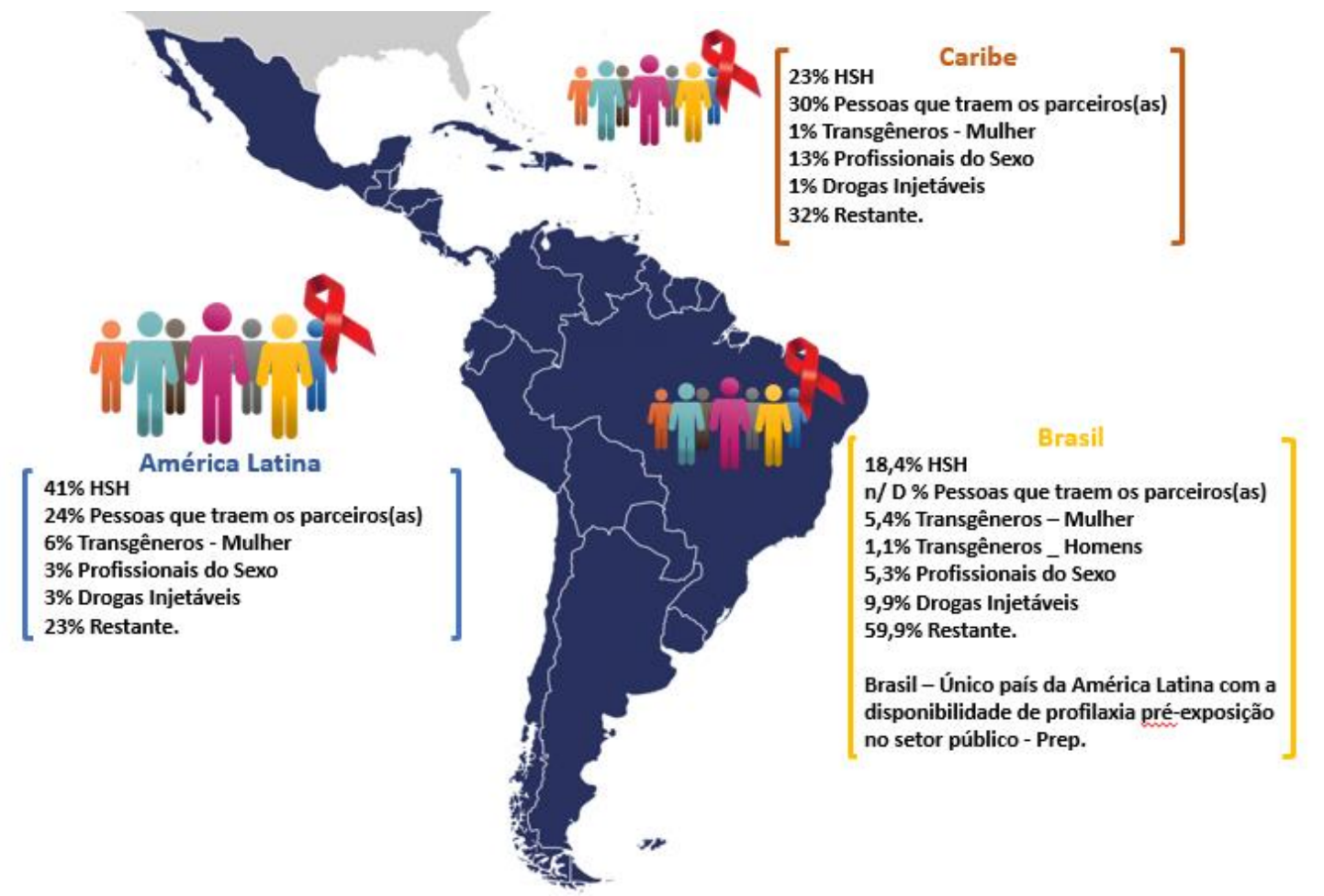

Fontes: UNAIDS - 2020

Dentre todos os países da América Latina, o Brasil é o único país em que a profilaxia pré-exposição (PREP) está disponível no sistema público de saúde (SUS). Possui classificação como estável a nível nacional mas com prevalências e taxas de novas infecções variando significativamente em cada região (AVERT, 2015). O país conta com uma porcentagem alta da população infectada através da via de transmissão heterossexual, quase $60 \%$ e com números relativamente baixos de infectados no grupo HSH (18\%) em comparação com os demais países da América Latina e Caribe, porém com informações e números representativamente baixo sobre o grupo de profissionais do sexo $(5,4 \%)$ e que provavelmente não representa uma realidade devido à baixa testagem dessas mulheres.

A faixa etária predominante na América Latina, Caribe e Brasil das pessoas infectadas é de 15 a 39 anos, sendo uma faixa observada como predominante em todos os ambientes de estudo, países, estados e municípios.

\begin{tabular}{llllll}
\hline Hygeia & Uberlândia - MG & Edição especial: X GeoSaude & Fev./2022 & p. 74-86 & Página 78
\end{tabular}




\section{Venezuela, Guiana e Suriname}

A caracterização da epidemia de HIV/AIDS nestes países é um desafio atual e carrega informações importantes (Tabela 1) uma delas é a faixa etária das pessoas infectadas com HIV, equivalente em todos os países, uma média de 15 a 39 anos.

Há uma estimativa de que 110 mil pessoas vivem com o HIV na Venezuela, um número expressivo de novas infecções em 2019 e uma razão bem distinta entre homens infectados e mulheres - mais de $10 \%$ de diferença. Conta com um número alto de jovens infectados, uma alta similar com o Brasil que também teve um aumento no número de jovens vivendo com HIV. São cerca de 11 mil jovens, de 15 a 24 anos, vivendo com o vírus na Venezuela e nem todos conhecem o seu diagnóstico. Apenas 70.00 pessoas das 110.000 que vivem com o HIV conhecem o seu estado atual, sendo então esse o número notificado. A porcentagem de HSH (22,30\%) e transgêneros $(35,80 \%)$ infectados são significativas. A Venezuela atualmente é um país com baixa testagem, baixa conscientização e baixo acesso à informação da população.

A Guiana estima que tenha 8.700 mil pessoas vivendo com HIV na sua região, menos de 500 novas infecções no último ano de 2019 e possui um equilíbrio entre a razão de homens e mulheres infectados. O número de jovens e adolescentes infectados na Guiana corresponde a menos de $5 \%$ respectivamente, e o país possui um programa de conscientização, testagem e informação recorrente entre a sua população. Em relação a estimativa de pessoas que vivem com o HIV, a Guiana possui um número relativamente alto de pessoas em tratamento resultando em indivíduos com carga viral indetectável e uma tentativa de melhor controle da epidemia. Um dos pontos mais consideráveis é o número de profissionais do sexo infectados no país, mais de $6 \%$.

No Suriname, país que faz fronteira com o Brasil, estima-se que 5.800 mil pessoas vivem com HIV e deste número, menos de 500 representam as novas infecções no último ano de 2019. A razão entre homens e mulheres infectados é semelhante com a Venezuela e também representa $10 \%$ de diferença entre ambos, e o número de jovens e adolescentes infectados é baixo. Porém, apenas 2.900 pessoas estão em constante acompanhamento e tratamento em setores de saúde, um número relativamente baixo em relação ao total da estimativa das pessoas vivendo com HIV. Em relação aos outros 2 países, o Suriname possivelmente tem o número mais alto de profissionais do sexo infectadas, é observado cerca de $10 \%$ do número total.

Tabela 1. Caracterização da Epidemia HIV/ AIDS -2020 na Venezuela, Guiana e Suriname.2020

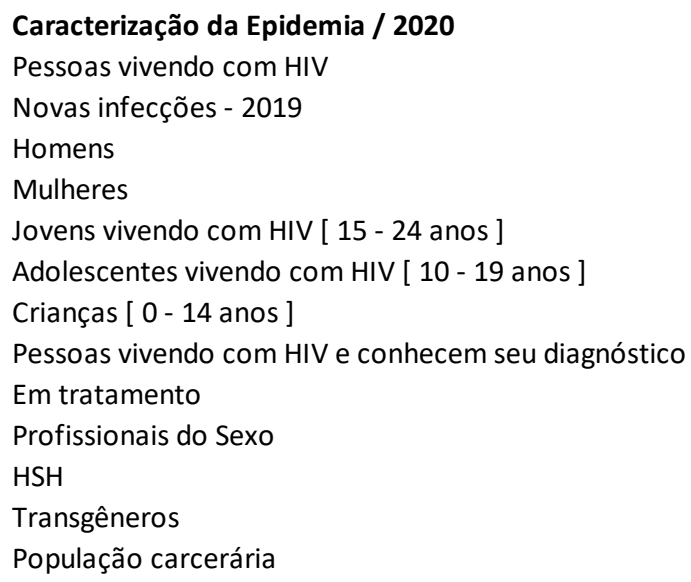

\begin{tabular}{|c|c|c|}
\hline Venezuela & Guiana & Suriname \\
\hline 110000 & 8700 & 5800 \\
\hline $5.200[4,73 \%]$ & \multicolumn{2}{|c|}{$<500[<200-<500][<5 \%]<500[<200-<500][<8 \%]$} \\
\hline $64.000[58,2 \%]$ & $4.300[49,4 \%]$ & $3.100[53,4 \%]$ \\
\hline $45.000[40,9 \%]$ & $4.100[47,1 \%]$ & $2.500[43,1 \%]$ \\
\hline $11.000[10 \%]$ & \multicolumn{2}{|c|}{$<500[<500-<500][<5 \%]<500[<500-<500][<8 \%]$} \\
\hline $4.900[4,4 \%]$ & $<500[<5 \%]$ & $<200[3,4 \%]$ \\
\hline $3.900[3,5 \%]$ & $<500[<5 \%]$ & $<200[<3,4 \%]$ \\
\hline $70.000[63,6 \%]$ & $8.100[93,1 \%]$ & $3.400[58,6 \%]$ \\
\hline $45.000[40,9 \%]$ & $6.000[68,9 \%]$ & $2.900[50 \%]$ \\
\hline $3,70 \%$ & $6,10 \%$ & $10,30 \%$ \\
\hline $22,30 \%$ & $4,90 \%$ & $16,60 \%$ \\
\hline $35,80 \%$ & $8,40 \%$ & $n / D$ \\
\hline $\mathrm{n} / \mathrm{D}$ & $1,70 \%$ & $n / D$ \\
\hline
\end{tabular}

Fontes: UNAIDS 2020 Entre colchetes, a porcentagem relacionada ao total de pessoas vivendo com HIV. 


\section{Guiana Francesa}

A Guiana Francesa é um departamento ultramarino francês situado na América do Sul e o mais afetado pelo HIV. Estima-se que 3.800 mil pessoas vivem com HIV nesse território e destes, 20 novas infecções pelo HIV foram notificadas no ano de 2018. É esperado que $10 \%$ do número total de pessoas ainda não conheçam o seu diagnóstico, no entanto, estima-se que mais de $90 \%$ dos infectados encontremse em tratamento. Diferentemente dos países da América Latina, a Guiana Francesa é um território que possui a maior proporção de pessoas infectadas em tratamento e também com carga viral indetectável (Tabela 2).

A faixa etária predominante dos infectados e o modo de transmissão são similares aos países vizinhos, pessoas de 15 a 39 anos e predominantemente infecções via heterossexual. Há um equilíbrio entre a razão de homens e mulheres infectados e identificada como uma epidemia de múltiplos parceiros, usuários de crack e frequentemente associada à prostituição( NACHER et al., 2020).

A Guiana Francesa é considerada uma terra de migrações, três a cada quatro pessoas nascidas no território francês são descendentes de migrantes (Mathieu Nacher, Elise Ouedraogo, Tiphanie Succo, Basma Guarmit, Félix Djossou, Laurence Stettler, Fernand Alvarez, Narcisse Elenga, Antoine Adenis, 2020), esse aspecto também é observado na caracterização da epidemia quando $85 \%$ dos infectados são de origem estrangeira (Tabela 2) e identificado 1,43\% dos infectados como garimpeiros. Dentre as notificações e dados franceses as maiores concentrações de pessoas em tratamento estão em dois territórios especificamente, mais de 1.300 pacientes fazem acompanhamento e tratamento em Cayenne, e quase 600 pacientes em Saint-Laurent-du-Maroni.

Tabela 2. Caracterização da Epidemia HIV/ AIDS -2020 na Guiana Francesa 2020

$\begin{array}{lr}\text { Caracterização da Epidemia / 2019 } & \text { Guiana Francesa } \\ \text { Pessoas vivendo com HIV } & 3800 \\ \text { Novas infecções em 2018 } & 20[0,5 \%] \\ \text { Não conhecem o diagnóstico } & {[10 \%]} \\ \text { Em tratamento } & {[91 \%]} \\ \text { Em tratamento c/ carga viral indetectavel } & {[94 \%]} \\ \text { № de dignósticos em Cayenne } & {[30 \%]} \\ \text { № de dignósticos em Saint-Laurent-du-Maroni } & {[45 \%]} \\ \text { Pessoas infectadas de origem estrangeira } & {[85 \%]} \\ \text { № de pacientes em Cayenne } & 1.304[34,3 \%] \\ \text { № de pacientes em Saint-Laurent-du-Maroni } & 599[15,8 \%] \\ \text { Mineiros / Garimpeiros } & {[1,43 \%]}\end{array}$

Fontes: (Mathieu Nacher, Elise Ouedraogo, Tiphanie Succo, Basma Guarmit, Félix Djossou, Laurence Stettler, Fernand Alvarez, Narcisse Elenga, Antoine Adenis, 2020)

\section{Região Norte: Amapá, Pará, Roraima e municípios fronteiriços}

Dentre os estados da região, o presente estudo se concentrou na caraterização dos estados de Amapá, Pará e Roraima, estados limítrofes com o escudo das Guianas. Todos eles possuem altos números de infectados, pessoas vivendo com HIV e expressivos números de notificações de casos de AIDS anualmente (Tabela 3). No último boletim epidemiológico, foi divulgado o ranking das maiores taxas de incidência de HIV em 2019, 3 dos 4 estados presentes são da região Norte: Roraima, Amapá e Amazonas(Boletim Epidemiológico HIV / AIDS / 2019, 2019).

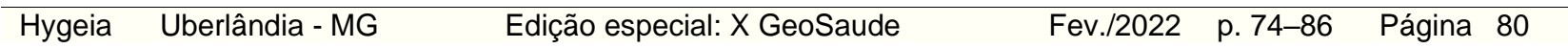


Tabela 3. Caracterização da Epidemia HIV/ AIDS na Região Norte -2019

\section{REGIÃO NORTE}

$\begin{array}{ll}\text { Casos de AIDS (1980 -2019) } & 65691 \\ \text { Casos de HIV notificados no SINAN (2007 - 2019) } & 26055 \\ \text { Casos de infecção por HIV - 2018 } & 5084 \\ \text { Média de casos de HIV ao ano (1980 a 2019) } & 4,4 \mathrm{mil} \\ \begin{array}{l}\text { Óbitos acumulados (1980 -2019) } \\ \multicolumn{1}{|c|}{\text { AP - RR - PA }}\end{array} & 17205 \\ \text { Pará (2007 - 2019) casos de HIV } & 10521 \\ \text { Roraima (2007 -2019) casos de HIV } & 1440 \\ \text { Amapá (2007- 2019) casos de HIV } & 1456 \\ \text { Pará (2000 - 2019) casos de AIDS } & 26931 \\ \text { Roraima (2000-2019) casos de AIDS } & 2570 \\ \text { Amapá (2000-2019) casos de AIDS } & 2497\end{array}$

Fontes: Boletim Epidemiológico - Secretária de Vigilância em Saúde; Ministério da Saúde. Número Especial (Dezembro de 2019)

A tabela (Tabela 4) apresenta uma caracterização demográfica da população nos municípios localizados na fronteira do extremo norte do Brasil, e uma caracterização da epidemia com os dados secundários de domínio público também nos municípios. A tabela é dividida entre indicadores populacionais, territoriais, educacionais e sociais, uma descrição desses indicadores na segunda coluna, a fonte e o ano/período desses dados e em colorido no topo os estados de estudo subdivididos em seus respectivos municípios fronteiriços. Ao final da tabela, encontra-se os dados relacionados ao HIV/AIDS dos estados e municípios, casos de AIDS, casos de HIV, a escolaridade predominante da população infectada e a via de transmissão predominante nesses locais.

Todos os municípios apresentam um equilíbrio na população no que se refere à idade sexualmente ativa e relativamente pertencente a faixa etária mais susceptível à infecção do HIV, observa-se uma alta população nessas regiões. Dez, dos onze municípios, contam com uma maioria de pessoas que trabalham no mesmo local, com a exceção do município de Oiapoque. Este município registra por sua vez cerca de mais de 400 pessoas trabalhando em país estrangeiro, muito possível que seja unicamente o território da Guiana Francesa.

É alto o número de pessoas que possuem domicilio próprio ou permanente em todos os municípios e também alto o número de pessoas que a nível educacional não possuem instrução ou possuem apenas o fundamental incompleto. $O$ indicador de migração torna-se importante para um inicial entendimento do fluxo de pessoas nesses municípios e reconhecimento dos seus locais de origem. Embora um número grande das populações tenha domicilio permanente ou próprio, há em todos os municípios um número expressivo de pessoas que não eram residentes locais em 2005 e números consideráveis de naturalidade diferente da região Norte, sendo principalmente da região Nordeste. 
Tabela 4. Caracterização da população em estudo; Caracterização da população dos estados do Amapá, Roraima, Pará e seus municípios fronteiriços no extremo norte do Brasil. Em conjunto com a caracterização da Epidemia HIV/ AIDS nos mesmos estados e municípios -2019.

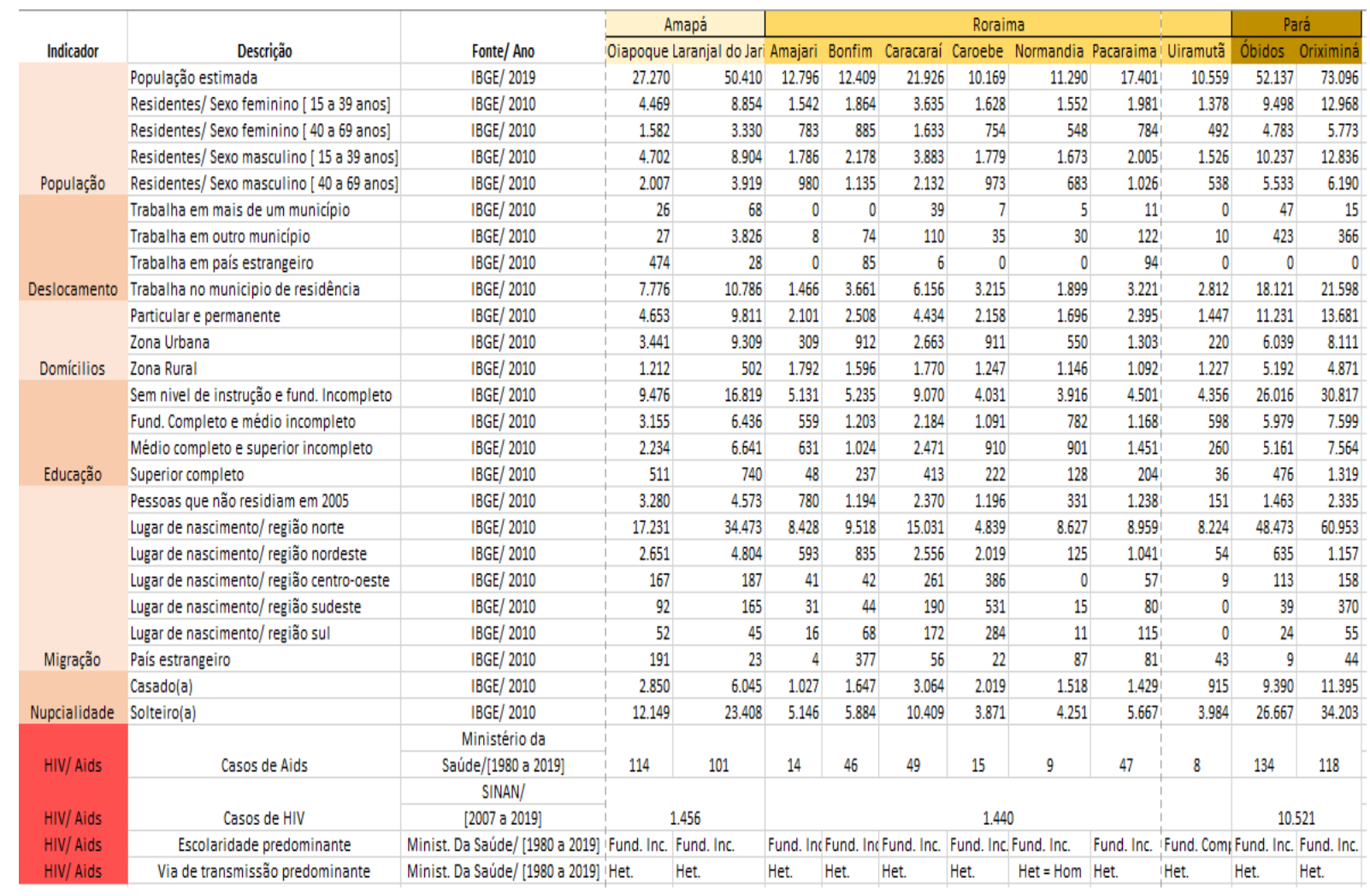

Fontes: Instituto Brasileiro de Geografia e Estatística (IBGE), Boletim Epidemiológico 2019 e Indicadores Datasus ambos disponíveis em domínio público pelo Ministério da Saúde.

Por fim, a tabela abaixo (Tabela 5) apresenta as taxas médias de incidência de AIDS calculadas em relação ao período de 2015 a 2019, na região de estudo Amapá, Roraima e Pará. Em conjunto, o cálculo das taxas também em cada município. No último boletim, a taxa média de incidência da região norte indicava 24,0 casos de AIDS por 100 mil habitantes (BRASIL, 2019). Observamos então o município de Pacaraima ultrapassando essa média regional, e pelo menos três municípios próximos deste número. Mesmo abaixo da média, todos os outros com altas taxas demonstrando números consideráveis de novos casos de AIDS em períodos específicos e um registro importante anualmente. 
Tabela 5. Taxas médias de incidência de AIDS no período de 2015 a 2019.

$\begin{array}{lc}\text { Estado } & \text { [ por } 100 \text { mil habitantes ] } \\ \text { Amapá } & 22,3 \\ \text { Roraima } & 33,3 \\ \text { Pará } & 23,3 \\ & \\ \text { Município } & \\ \text { Oiapoque } & 14,9 \\ \text { Laranjal do Jari } & 17,6 \\ \text { Amajari } & 10,4 \\ \text { Bonfim } & 15,1 \\ \text { Caracaraí } & 18,2 \\ \text { Caroebe } & 14,7 \\ \text { Normandia } & 1,9 \\ \text { Pacaraima } & 27,5 \\ \text { Uiramutã } & 6,1 \\ \text { Obidos } & 20,9 \\ \text { Oriximiná } & 11,8 \\ \text { CI = Soma do número de casos novos da doença por ano do período (/5) } & \times 100.000 \text { habitantes } \\ \quad \text { População sob risco (estimativa da população no ano médio) } \\ \text { Cl (Coeficiente de incidência) utilizado foi média entre o período de 2015 a 2019. Ano médio 2017. }\end{array}$

\section{DISCUSSÃO}

Mais precisamente há vinte anos já se publicava alertando sobre as mudanças no perfil da AIDS no Brasil, devido a difusão geográfica da doença a partir dos grandes centros urbanos em direção aos municípios de médio e pequeno porte, o aumento da transmissão por via heterossexual e o aumento de usuários de drogas injetáveis (BRITO et al., 2001). Basicamente nos mostra um retrato da atual epidemia de AIDS na América Latina, Caribe e Brasil. Uma difusão geográfica da doença de forma nada regular, concentrada em determinadas regiões especificas, avançando cada vez mais dos centros urbanos para municípios de menores, aumento significativo de mulheres infectadas, gerando quadros constantes de infecção predominantemente heterossexual e anualmente novos casos de HIV e AIDS.

Além de uma epidemia multifacetada e mudando conformidades predominantes de forma gradativa, a fronteira conta com a circulação de uma variante de origem caribenha - HIV Tipo 1, subtipo B, variante BCAR - amplamente distribuída na Guiana, Suriname e Guiana Francesa e concomitantemente também já circulando em estados da região Norte do Brasil.

A América Latina e Caribe possuem um grande desafio, pois embora ultimamente se perceba uma alta adesão ao tratamento e uma diminuição no número de mortes, o número de novas infecções aumenta consideravelmente. Esse aumento pode ter relação direta com falta de informações, deficiente conscientização da população e falhas conjuntas em relação a prevenção. A região Norte do Brasil também faz-se perceber o negligenciamento por parte dos poderes públicos em déficit de informações e prevenção da população em relação ao HIV.

O Brasil, diferentemente dos demais países da América Latina, possui fortes respostas ao combate contra a AIDS e o HIV: disponibiliza gratuitamente o tratamento e o teste, foi um dos primeiros países a fornecer o autoteste, desafiou empresas farmacêuticas na década de 90 por novas versões dos

\begin{tabular}{lllll}
\hline Hygeia Uberlândia - MG $\quad$ Edição especial: X GeoSaude & Fev./2022 & p. 74-86 & Página 83
\end{tabular}


antirretrovirais, é o país que mais compra e distribui preservativos e que em 2013 começou a fornecer tratamento gratuito a todos os indivíduos que vivem com o HIV. Não obstante, a região Norte notificou 5 mil novos casos de infecções no ano de 2018 e a estabilidade nacional divulgada nos boletins epidemiológicos não corresponde com a realidade, pois anualmente é observado um acréscimo no número de novas infecções de HIV e novos casos de AIDS nos estados do Norte do país.

Adicionalmente aos desafios de cada país em relação ao controle da epidemia de HIV/AIDS, a Venezuela, a Guiana, o Suriname, e a Guiana Francesa, e o Brasil compartilham fronteiras, culturais e vidas cabendo mencionar que todos esses territórios estão intimamente relacionados com o Caribe.

As fronteiras são construções sociais, políticas, uma prática de pluralidade. Movimentos de um mundo contemporâneo caracterizado pela busca urgente de uma sociedade em rede(Gomes et al., 2020) e a AIDS é um dos maiores desafios atuais altamente associado à relações sociais principalmente sexuais.

A Guiana Francesa pode ser considerada um dos exemplos mais ativos da relação da mobilidade social e do HIV atualmente. Trata-se de um território europeu na América do Sul, que tem praticamente eliminado as filas ativas de casos de AIDS e HIV, porém ainda observa constantemente e anualmente novos casos de pessoas vivendo com HIV no seu território e mais de $80 \%$ das pessoas que vivem com o virus são de origem estrangeira. A Guiana é um território de migrantes e intensa mobilidade populacional, mesmo que de forma clandestina e tem um imenso desafio de atuação conjunta, pois os problemas enfrentados por este território europeu é um reflexo dos problemas enfrentados nos países vizinhos.

A Venezuela possui atualmente as maiores taxas de gravidez na adolescência da América Latina, embora tenha uma abrangente educação sexual (não obrigatória) nas escolas. É um país atingido atualmente por grave crise econômica, o que dificulta a aquisição e distribuição de produtos médicos inclusive tratamentos e testes para HIV(AVERT, 2015).

No Suriname, profissionais do sexo masculinos e transgêneros tendem a ser mais afetados pelo HIV do que profissionais do sexo cis-mulheres. Em 2014 estimou-se que 69\% dos homens profissionais do sexo no Suriname viviam com HIV em comparação as mulheres profissionais do sexo (4\%). Esses países possuem inúmeros desafios como: migração, desigualdades sociais, diversidade de língua e cultura, porém esses desafios precisam estar em harmonia com um combate inteligente e assertivo contra o HIV.

Onze municípios do Brasil fazem fronteira diretamente com esses países no extremo norte da América do Sul, tornando-os protagonistas das estratégias e resoluções para os desafios comuns. Se o número de novos casos de AIDS e novas infecções continuam aumentando, uma estratégia de controle fundamental é a conscientização e informação da população à respeito das formas de prevenção do HIV. Os municípios em foco convivem diariamente com grande movimentação de pessoas nas zonas de fronteira, dado que em Oiapoque (AP), Bonfim (RR) e Pacaraima (RR) o número de pessoas que trabalham em países estrangeiros é significativo.

Oiapoque (AP) é separado pelo rio Oiapoque da cidade-gêmea de Saint-Georges de l'Oyapock, na Guiana Francesa, Bonfim (RR) faz divisa com a cidade de Lethem, na Guiana e é separado pelo rio Tacutu da cidade gêmea de Lethem (Guiana) e o município de Pacaraima (RR) tem fronteira terrestre com a cidade-gêmea de Santa Elena de Uairén, na Venezuela.

Saint Georges é a primeira cidade de contato dos brasileiros com a Guiana Francesa. É constante a movimentação de barcos entre o Oiapoque, as trocas entre euro e real são diárias, as compras do lado francês e nas noites tranquilamente se encontra franceses no Brasil e brasileiros frequentando bares do outro lado do rio.

A cidade de Lethem, por sua vez, é conhecida pelas compras e comércio barato local e de fácil acesso da população de Bonfim. O município brasileiro de Pacaraima é o primeiro acesso dos venezuelanos, constantes profissionais de sexo nas ruas e intensa comunicação entre os municípios em geral. Esses mesmos municípios foram os que mais registraram casos de AIDS na região. É uma característica atual

\begin{tabular}{llllll}
\hline Hygeia Uberlândia - MG & Edição especial: X GeoSaude & Fev./2022 & p. 74-86 Página 84
\end{tabular}


que a população vivente com HIV não tenha instrução ou possua apenas o fundamental completo, além dessa característica observada, a via de transmissão em todos os municípios é a via heterossexual.

A facilidade de mobilidade e movimentação não pode ser confundida com algo desastroso e ruim, é um desafio dos países por parte dos poderes públicos entenderem melhor essa mobilidade, respeitando as populações e desenhando eficiente construção de estratégias inteligentes de conscientização e informação. A prevenção precisa ser um dos passos mais importantes antes mesmo de tratamento e teste em relação a AIDS e HIV.

A situação da AIDS na fronteira explicita as diferenciações regionais e locais, demonstra com clareza os desafios dos países vizinhos e abre questionamentos para estudos aprofundados sobre processos migratórios, sociais e a relação desses processos com a epidemia de AIDS. O presente trabalho tem visa continuar os estudos, de apresentar construções sólidas abrindo possibilidades entendimento e de possíveis melhorias para as regiões transfronteiriças, comunidades e portadores de HIV de ambos os países vizinhos do Brasil.

\section{AGRADECIMENTOS}

O presente trabalho foi realizado com o apoio incondicional da Fundação Oswaldo Cruz e da Coordenação de Aperfeiçoamento de Pessoal de Nível Superior - Brasil (CAPES).

\section{REFERÊNCIAS}

AVERT. HIV and AIDS in Latin America regional overview, 2015. Disponível em: http://www.avert.org/professionals/HIV-around-world/latin-america/overview

BRASIL. Ministério da Saúde. Secretaria de Vigilância Em Saúde. Boletim Epidemiológico HIV/AIDS | 2016, Brasília, DF, 2016.

BRASIL. Ministério da Saúde. Secretaria de Vigilância Em Saúde. Boletim Epidemiológico HIV/AIDS | 2019, Brasília, DF, 2019.

BRASIL. Ministério da Saúde. Secretaria de Vigilância Em Saúde. Boletim Epidemiológico HIV / AIDS | 2020, v.1, n.68, 2020.

BRITO, A. M.; CASTILHO, E. A.; SZWARCWALD, C. L. AIDS and HIV infection in Brazil: a multifaceted epidemic. Revista Da Sociedade Brasileira de Medicina Tropical, v.34, n. 2, p.207217, 2001. https://doi.org/10.1590/S0037-86822001000200010

DIVINO, F. C.P. Filodinâmica das variantes não-pandêmicas do Vírus da Imunodeficiência Humana Tipo 1 Subtipo B no Brasil. Dissertação (Mestrado em Biologia Computacional e Sistemas) - Rio de Janeiro: Fundação Oswaldo Cruz, Instituto Oswaldo Cruz, 2017.

DIVINO, F.; DE CORADO, A. L. G.; NAVECA, F. G.; STEFANI, M. M. A.; BELLO, G. High prevalence and onward transmission of non-pandemic HIV-1 subtype B clades in northern and northeastern Brazilian regions. PLoS ONE, n.11, v.9, p. 1-14, 2016. https://doi.org/10.1371/journal.pone.0162112

GOMES, M. DO S. M.; MENEZES, R. A. DE O.; VIEIRA, J. L. F.; MENDES, A. M.; SILVA, G. DE V.; PEITER, P. C.; SUÁREZ-MUTIS, M. C.; FRANCO, V. DA C.; COUTO, Á. A. R. D.; MACHADO, R. L. $D$. Malária na fronteira do Brasil com a Guiana Francesa: a influência dos determinantes sociais e ambientais da saúde na permanência da doença. Saúde e Sociedade, v.29 n. 2, p. 1-14, 2020. https://doi.org/10.1590/s0104-12902020181046

HOCHMAN, G.; ARMUS, D. (Org). Cuidar, controlar, curar ensaios históricos sobre saúde e doenças na América Latina e Caribe. Rio de Janeiro: Fiocruz, 2004. https://doi.org/10.7476/9788575413111

NACHER, M.; OUEDRAOGO, E.; SUCCO, T.; GUARMIT, B.; DJOSSOU, F.; STETTLER, L.; ALVAREZ, F.; ELENGA, N.; ADENIS, A.; COUPPIÉ, P. L'infection VIH en Guyane, revue historique et tendances actuelles. Bulletin Epidémiologique Hébdomadaire, v. 2-3, p. 43-51, 2020.

\begin{tabular}{lllll}
\hline Hygeia & Uberlândia - MG $\quad$ Edição especial: X GeoSaude & Fev./2022 & p. 74-86 & Página 85
\end{tabular}


PEITER, P. C. (2005). A Geografia da Saúde na Faixa de Fronteira Continental do Brasil na Passagem do Milênio. Tese (Doutorado em Geografia). Rio de Janeiro: Universidade Federal do Rio de Janeiro, 2005.

WHITEHEAD, M. The concepts and principles of equity and health. International Journal of Health Services, v.22, n. 3, p. 429-445, 1992. https://doi.org/10.2190/986L-LHQ6-2VTE-YRRN 